\section{Standardabweichung, gepoolte}

R.-D. Hilgers ${ }^{1}$, N. Heussen ${ }^{1}$ und S. Stanzel ${ }^{2}$

${ }^{1}$ Institut für Medizinische Statistik, Universitätsklinikum der RWTH Aachen, Aachen, Deutschland

${ }^{2}$ DKFZ Heidelberg, Heidelberg, Deutschland

Englischer Begriff pooled standard deviation

Definition Die gepoolte Standardabweichung ist definiert als die Wurzel aus der gepoolten Varianz ( $\triangleright$ Varianz, gepoolte).

Beschreibung Die gepoolte Standardabweichung misst die gemeinsame $>$ Variabilität innerhalb von 2 oder mehr Stich- proben (s. \ Stichprobe), deren Messergebnisse miteinander kombiniert werden sollen. Im allgemeinen Fall von k Stichproben mit Stichprobenumfängen $n_{l},(\ldots), n_{k}$ ergibt sich die gepoolte $>$ Standardabweichung als eine Art „fallzahlgewichtete Mittelung" der Standardabweichungen $\mathrm{s}_{1},(\ldots), \mathrm{s}_{\mathrm{k}}$ der k einzelnen Stichproben:

$$
\mathrm{s}_{\mathrm{p}}=\sqrt{\frac{1}{\mathrm{~N}-\mathrm{k}} \sum_{\mathrm{i}=1}^{\mathrm{k}}\left(\mathrm{n}_{\mathrm{i}}-1\right) \times \mathrm{s}_{\mathrm{i}}^{2}} ; \mathrm{N}=\sum_{\mathrm{i}=1}^{\mathrm{k}} \mathrm{n}_{\mathrm{i}}
$$

\section{Literatur}

Glantz SA (1992) Primer of biostatistics, 3. Aufl. McGraw-Hill, New York 